University of Nebraska - Lincoln

DigitalCommons@University of Nebraska - Lincoln

Biological Systems Engineering: Papers and

Publications

Biological Systems Engineering

$10-2007$

\title{
Bioluminescence Imaging for Assessment and Normalization in Transfected Cell Arrays
}

\author{
Angela K. Pannier \\ University of Nebraska-Lincoln, apannier2@unl.edu \\ Eric A. Ariazi \\ Fox Chase Cancer Center, Philadelphia, PA \\ Abigail D. Bellis \\ Northwestern University,, abigail.stringer@northwestern.edu \\ Zain Bengali \\ Northwestern University, \\ V. Craig Jordan \\ Northwestern University, \\ See next page for additional authors
}

Follow this and additional works at: https://digitalcommons.unl.edu/biosysengfacpub

Part of the Biological Engineering Commons

\footnotetext{
Pannier, Angela K.; Ariazi, Eric A.; Bellis, Abigail D.; Bengali, Zain; Jordan, V. Craig; and Shea, Lonnie D., "Bioluminescence Imaging for Assessment and Normalization in Transfected Cell Arrays" (2007). Biological Systems Engineering: Papers and Publications. 146.

https://digitalcommons.unl.edu/biosysengfacpub/146
}

This Article is brought to you for free and open access by the Biological Systems Engineering at DigitalCommons@University of Nebraska - Lincoln. It has been accepted for inclusion in Biological Systems Engineering: Papers and Publications by an authorized administrator of DigitalCommons@University of Nebraska Lincoln. 


\section{Authors}

Angela K. Pannier, Eric A. Ariazi, Abigail D. Bellis, Zain Bengali, V. Craig Jordan, and Lonnie D. Shea 
Published in Biotechnology and Bioengineering 98:2 (October 1, 2007), pp. 486-497; doi: 10.1002/bit.21477

Copyright @ 2007 Wiley Periodicals, Inc. Used by permission. http://www.interscience.wiley.com

Submitted March 21, 2007; accepted April 12, 2007; published online May 7, 2007.

\title{
Bioluminescence Imaging for Assessment and Normalization in Transfected Cell Arrays
}

\author{
Angela K. Pannier, ${ }^{1}$ Eric A. Ariazi, ${ }^{2}$ Abigail D. Bellis, ${ }^{3}$ \\ Zain Bengali, ${ }^{1}$ V. Craig Jordan, ${ }^{2}$ Lonnie D. Shea ${ }^{3,4}$ \\ 1. Department of Interdepartmental Biological Sciences, Northwestern University, Evanston, Illinois \\ 2. Fox Chase Cancer Center, Philadelphia, Pennsylvania \\ 3. Department of Chemical and Biological Engineering, Northwestern University, Evanston, Illinois \\ 4. Robert H. Lurie Comprehensive Cancer Center, Northwestern University, Chicago, Illinois 60611 \\ Corresponding author - L. D. Shea, Department of Chemical and Biological Engineering, Northwestern University, \\ 2145 Sheridan Rd E156, Evanston, Illinois 60208-3120; tel 847 491-7043, fax 847 491-3728, e-mail l-shea@northwestern.edu
}

\begin{abstract}
Transfected cell arrays (TCAs) represent a high-throughput technique to correlate gene expression with functional cell responses. Despite advances in TCAs, improvements are needed for the widespread application of this technology. We have developed a TCA that combines a two-plasmid system and dual-bioluminescence imaging to quantitatively normalize for variability in transfection and increase sensitivity. The two-plasmids consist of: (i) normalization plasmid present within each spot, and (ii) functional plasmid that varies between spots, responsible for the functional endpoint of the array. Bioluminescence imaging of dual-luciferase reporters (renilla, firefly luciferase) provides sensitive and quantitative detection of cellular response, with minimal post-transfection processing. The array was applied to quantify estrogen receptor $\alpha(E R \alpha)$ activity in MCF-7 breast cancer cells. A plasmid containing an ER $\alpha$-regulated promoter directing firefly luciferase expression was mixed with a normalization plasmid, complexed with cationic lipids and deposited into an array. ER induction mimicked results obtained through traditional assays methods, with estrogen inducing luciferase expression 10-fold over the antiestrogen fulvestrant or vehicle. Furthermore, the array captured a dose response to estrogen, demonstrating the sensitivity of bioluminescence quantification. This system provides a tool for basic science research, with potential application for the development of patient specific therapies.
\end{abstract}

Keywords: transfected cell array, bioluminescence imaging, substrate-mediated gene delivery, estrogen receptor, breast cancer

\section{Introduction}

Analysis of multiple pathways or genes in a parallel format can be achieved using a transfected cell array, a highthroughput technique to correlate gene expression with functional cell responses, based on gene delivery from a substrate that supports cell adhesion (Bengali et al., 2005; Pannier et al., 2005; Segura and Shea, 2002; Segura et al., 2003). While traditional microarrays can quantify the expression level of thousands of genes, they cannot accurately describe the functional activity of these genes in a cellular and physiological context (Pepperkok and Ellenberg, 2006). Transfected cell arrays present a powerful approach to study gene function in the context of a living cell, allowing proteins to be translated and folded correctly and to interact within the environment of the cell. Additionally, a large number of genes can be potentially screened in parallel for induction or repression of a given function (Palmer and Freeman, 2005). Transfected cell arrays offer compact, economical, and high-throughput 
analysis in living cells that provides greater consistency across assays and facilitates comparisons between conditions, while reducing the amount of reagents and cell numbers required, which is an important factor for difficult to prepare cell types (Hook et al., 2006; Palmer and Freeman, 2005).

Since the original report on transfected cell arrays (Ziauddin and Sabatini, 2001), reverse transfection has been employed in several high-throughput cell based microarrays to screen for gene function or activity (8-20). Reverse transfection involves printing mixtures of different plasmids and gelatin into specific domains onto a substrate. A lipid-based transfection agent is then floated over the array, and cells are subsequently seeded to form a living cell microarray of locally transfected cells in a lawn of nontransfected cells. The first transfected cell array was used to analyze genes for phosphotyrosine activity and identified six genes; five genes that encode known tyrosine kinase proteins and one that encodes a protein of unknown function (Ziauddin and Sabatini, 2001). Transfected cell arrays have since been applied to study signaling pathways (Webb et al., 2003), screen antibody fragments (Delehanty et al., 2004b), identify possible new lysophosphatidic acid receptors (Lee et al., 2006), perform protein localization studies (Hu et al., 2005, 2006), screen for proapoptotic genes (Mannherz et al., 2006; Palmer et al., 2006), and annotate protein function (Hodges et al., 2005). The transfected cell array has also been adapted to high-throughput RNAi studies (Mousses et al., 2003), specifically for the analysis of spindle formation (Silva et al., 2004), secretory pathways (Erfle et al., 2004), and chromosome segregation and nuclear structure in a time-lapse system (Neumann et al., 2006).

Technological improvements have enhanced the capabilities of the arrays, yet further advancements are required for widespread application of this system. Most efforts have focused on increasing transfection efficiency within the array by using preformed complexes (Delehanty et al., 2004a, 2004b; Erfle et al., 2004; Hodges et al., 2005; Mousses et al., 2003; Pannier et al., 2005; Redmond et al., 2004; Silva et al., 2004; Yoshikawa et al., 2004), incorporating fibronectin (Yoshikawa et al., 2004), atelocollagen (Honma et al., 2001), and recombinant proteins (Redmond et al., 2004) with plasmid or DNA complexes, manipulating substrate hydrophobicity (Delehanty et al., 2004a), or coating cationic polymer and collagen onto surfaces prior to transfection (Chang et al., 2004). Micropatterning strategies have also been used to fabricate arrays with improved transfection, using self-assembled monolayers to pattern DNA (Pannier et al., 2005; Yamauchi et al., 2004a) or siRNA (Fujimoto et al., 2006) complex immobilization on gold slides or electrodes (Yamauchi et al., 2004b, 2005). Arrays have been formed with dendrimers (How et al., 2004) and viral vectors (Bailey et al., 2006; Hobson et al., 2003; Michiels et al., 2002) for enhanced gene delivery, magnetic beads (Isalan et al., 2005) or hydrogels (Peterbauer et al., 2006) to localize cells and vectors, and for alternative cell types, including Drosophila (Wheeler et al., 2004) and nonadherent cells (Kato et al., 2004). Further improvements are needed to ac- commodate issues with transfection efficiency, spot-to-spot variability, normalization, post-transfection processing, sensitivity, image acquisition and quantification, cell types that are difficult to transfect, as well as to expand the biological endpoints.

In this report, we combine a two-plasmid system and dual-bioluminescence imaging (Pichler et al., 2005; Rafiq et al., 1998; Rutter et al., 1998) to quantify array output, normalize for variability in transfection efficiency, and address sensitivity concerns to overcome known shortcomings of the transfected cell arrays. Soft lithography principles (Xia and Whitesides, 1998) were used to create the transfected cell array, in which a rubber mold was used to confine deposition of preformed DNA complexes to designated regions of the substrate and pattern transfection upon cell seeding. Larger spot sizes were employed in the array to provide sufficient numbers of transfected cells and increase the reliability and statistical relevance of quantitative data obtained from each spot (Fujimoto et al., 2006; Hodges et al., 2005). To account for inherent variances in transfection between spots, transfection efficiency and protein production were normalized with the addition of a second plasmid within all spots of the array, encoding renilla luciferase driven by a constitutive promoter, in addition to a primary regulated plasmid reporting on the activation of a transcription factor through firefly luciferase expression. Bioluminescence imaging of the two luciferase reporters allows for quick image acquisition with no post-transfection processing.

We illustrate the utility of the array to quantitatively assay for the activity of a transcription factor in response to various activators or inhibitors. The estrogen receptor a $(E R \alpha)$ pathway in ER-positive, estrogen-responsive breast cancer cells was analyzed in an array format, using an ERE-regulated promoter reporter system. ER $\alpha$ expression is an important biomarker for determining treatment course for clinical breast cancer (Ariazi et al., 2006; Pearce and Jordan, 2004). Estrogens, via ER $\alpha$, act as potent mitogens of ER-positive breast cancer (Ikeda and Inoue, 2004). In our plasmid system, the ER-regulated promoter directs firefly luciferase expression in response to transcriptional activation by $17 \beta$-estradiol $\left(\mathrm{E}_{2}\right)$-bound ER $\alpha$. Bioluminescence imaging was employed to quantify luciferase-based light emission resulting from the ER-regulated and normalization plasmids. The array can thus be employed to analyze the induction and inhibition of the transcription factors, which could be used in a high-throughput format to elucidate gene function and cellular pathways responsible for diseases (Hook et al., 2006; Palmer and Freeman, 2005; Pepperkok and Ellenberg, 2006).

\section{Materials and Methods}

\section{Cells}

All studies used ER-positive MCF-7/WS8 mammary carcinoma cells, clonally derived from MCF-7 cells by selection for sensitivity to growth simulation by $\mathrm{E}_{2}$ (Jiang et al., 1992; 
Levenson and Jordan, 1997). Cells were cultured in fully estrogenized, phenol red-containing RPMI-1640 media supplemented with $10 \%$ fetal bovine serum (FBS), $100 \mu \mathrm{M}$ nonessential amino acids, $100 \mathrm{U}$ antibiotic/antimycotic, $2 \mathrm{mM}$ L-glutamine, and $6 \mathrm{ng} / \mathrm{ml}$ insulin and maintained at $37^{\circ} \mathrm{C}$ in a humidified $5 \% \mathrm{CO}_{2}$ atmosphere. Prior to transfecting cells for an experiment, cells were cultured under estrogenfree conditions by substituting phenol red-free RPMI-1640 and dextran-coated charcoal-treated FBS in the medium. For experiments in which transfected cells were assayed in 24-well plates using a luminometer, or imaged in arrays using a CCD camera, cells were cultured under estrogen-free condition for 4 days or $18 \mathrm{~h}$, respectively, prior to seeding. Culture in estrogen-free media for either time period allowed adequate time for up-regulation of ER protein levels due to $E_{2}$ withdrawal (data not shown), while the shorter culture period enhanced cell viability in the array. All media and media components were purchased from GIBCO/ Invitrogen (Carlsbad, CA).

\section{Plasmids}

Plasmids were purified from bacteria culture using Qiagen (Valencia, CA) reagents and stored in Tris-EDTA buffer solution (10 mM Tris, 1 mM EDTA, $\mathrm{pH}$ 7.4) or water at $-20^{\circ} \mathrm{C}$. Plasmid pEGFP-LUC encodes both the enhanced green fluorescent protein (EGFP) and firefly luciferase protein, under the direction of a CMV promoter (Clontech, Mountain View, CA). Plasmid pLUC encodes the firefly luciferase gene in the pNGVL1 (National Gene Vector Labs, University of Michigan) vector backbone with a CMV promoter. Estrogen-responsive plasmid pERE(3×)TK-ffLUC (Catherino and Jordan 1995) contains three tandem copies of the palindromic estrogen response element (ERE) sequence, placed upstream of a minimal herpes simplex thymidine kinase (TK) promoter, directing expression of the firefly luciferase coding sequence in response to transcriptional activation by estradiol $\left(\mathrm{E}_{2}\right)$-bound $\mathrm{ER} \alpha$, followed by recruitment of cofactor complexes and basal transcriptional machinery. Plasmid pTK-rLUC (phRL-TK, Promega, Madison, $\mathrm{WI}$ ) contains the minimal TK promoter driving expression of a humanized renilla luciferase and was used for normalization of the firefly luciferase plasmids. Plasmid p $\beta$ GAL encodes for nuclear-targeted $\beta$-galactosidase in the pNGVL1 (National Gene Vector Labs, University of Michigan) vector backbone with a CMV promoter and was used for control spots on the array.

\section{DNA Complex Formation}

DNA complexes were formed with Lipofectamine 2000 (Invitrogen), Lipofectamine LTX (Invitrogen) or Effectene (Qiagen), following manufacturer's instructions. Briefly, for both Lipofectamine 2000 and Lipofectamine LTX, DNA complexes were formed at a DA/lipid ratio of 1:2 in serum-free, Opti-MEM media (Invitrogen), by adding transfection reagent diluted in media dropwise to DNA in media, mixing by gentle pipeting, and then incubating for 20 min. Effectene complexes were formed by diluting DNA into EC buffer, to which the Enhancer buffer was added at a DNA to Enhancer ratio of 1:8. After 2-5 min of incubation at room temperature, the Effectene transfection reagent was then added to the DNA/Enhancer mixture at a DNA to Transfection reagent ratio of 1:4. After incubation at room temperature for $10 \mathrm{~min}$, complexes were diluted with serum-free media before addition to surfaces or cells. DNA in complexes containing multiple plasmids was extensively mixed prior to complex formation. For induction studies in estrogen-free media, phenol red-free Opti-MEM media was used for complex formation.

\section{Multiwell Dish Format Reporter Gene Assays}

Multiwell dish format reporter gene assays were performed to compare the ability of surface delivery of complexes to monitor ER $\alpha$ response in comparison to traditional bolus delivery. For surface delivery, the surface of wells of a 24-well plate (Becton Dickinson, Franklin Lakes, $\mathrm{NJ})$ were serum coated by incubation with dextran-coated charcoal-stripped FBS $(10 \%$ in $1 \times$ PBS, pH 7.4, $380 \mu \mathrm{L})$ for $18 \mathrm{~h}$ at $4^{\circ} \mathrm{C}$, followed by two wash steps with PBS (Bengali et al., 2005). Complexes were then immobilized following complex formation, as described above, by incubation of DNA complexes $(475 \mu \mathrm{L})$ with the serum-coated wells for $2 \mathrm{~h}$. After complex incubation, the wells were washed twice with Opti-MEM (for Lipofectamine 2000 complexes) or EC buffer (for Effectene complexes) and 250,000 MCF-7 cells (which had been cultured in estrogen-free media for 4 days) were seeded onto the immobilized DNA-lipid complexes in each well.

For bolus delivery, MCF-7 cells, which had been cultured in estrogen-free media for 4 days, were seeded in estrogen-free medium into 24-well plates at densities of 125,000 cells per well. Eighteen hours later, complexes, formed as described above, were diluted in antibiotic-free, estrogen-free media and then added to the cells.

For both surface and bolus delivery, complexes contained both the pERE(3x)TK-ffLUC plasmid and the normalization plasmid, pTK-rLUC, at a ratio of 4:1. Total DNA amounts added for surface delivery ranged from 0.13 to $1.32 \mu \mathrm{g} / \mathrm{cm}^{2}(0.25-2.5 \mu \mathrm{g}$ per well) and 0.05 to $0.26 \mu /$ $\mathrm{cm}^{2}(0.025-0.5 \mu \mathrm{g}$ per well) for bolus delivery. Given binding profiles, these ranges result in approximately the same amount of DNA bound to the surface as delivered as a bolus (Bengali et al., 2005).

Immediately after complex addition for bolus delivery and $4 \mathrm{~h}$ after cell seeding for surface delivery, cells were treated with combinations of $\mathrm{E}_{2}$ (Sigma-Aldrich, St. Louis, $\mathrm{MO})$, the complete anti-estrogen fulvestrant [(FUL), also termed ICI 182,780, Tocris Bioscience, Ellisville, MO] or vehicle controls. $\mathrm{E}_{2}$ and FUL were both dissolved in ethanol and diluted in estrogen-free media to obtain the indicated concentrations ( $10^{-12}$ to $10^{-9} \mathrm{M}$ for $\mathrm{E}_{2} ; 10^{-6} \mathrm{M}$ for FUL) prior to addition to cells. Ethanol diluted in estrogen-free media served as the vehicle control. Cells were harvested 
and assayed for firefly and renilla luciferase reporter gene activities $48 \mathrm{~h}$ after transfection using the Dual- Luciferase Reporter assay system (Promega). In this dual-luciferase system, firefly and renilla luciferases are measured sequentially, in a single well. These measurements are accomplished by adding the firefly luciferase substrate first, measuring luminescence, and then adding reagents that quench the firefly luciferase reaction and simultaneously provide the renilla luciferase substrate, followed by measuring renilla luciferase activity. The dual-luciferase assays were carried out using an automated microplate luminometer equipped with dual-injection ports (Mithras LB 940, Berthold Technologies, Oak Ridge, TN). Relative dual-luciferase activity was calculated by dividing the luminescent signal from the firefly reporter gene by the renilla luminescent signal.

\section{Array Fabrication}

Soft lithography techniques were used to pattern DNA complex deposition. A polydimethylsiloxane (PDMS) mold was fabricated by curing PDMS into thin, flat disks. Briefly, PDMS was prepared in a 10:1 (v/v) ratio of Silicone Elastomer-184 and Silicone Elastomer Curing Agent184 (Sylgard 184, Dow Corning, Midland, MI) by mixing the base and curing agent at least 50 times using a syringe mixing system. After allowing all air bubbles to escape, the PDMS was poured directly into a polystyrene tissue culture dish (100 mm, Corning, Corning, NY) and cured at $60^{\circ} \mathrm{C}$ for approximately $2 \mathrm{~h}$. The cured PDMS was removed from the dish and rods of precise diameters were then used to punch holes into the PDMS, with diameters of $2.4 \mathrm{~mm}$. The PDMS mold was rinsed in 70\% ethanol, oxidized using oxygen plasma and then reversibly sealed to polystyrene microscope slides (Nunc, Rochester, NY), which were fitted into custom-fabricated Teflon slide holders. The holes in the PDMS mold, termed microwells, served as reservoirs for deposition of DNA complexes onto the polystyrene slide. After $2 \mathrm{~h}$ of complex deposition in humid conditions, the PDMS mold was peeled away from the polystyrene, and the slide was rinsed thoroughly with Opti-MEM. For all array studies, DNA concentrations ranged from 0.007 to $0.021 \mu \mathrm{g} / \mu \mathrm{L}$, with 2.2 to $4 \mu \mathrm{L}$ of complex volume added to the microwells of the PDMS mold.

To visualize DNA complex immobilization on the array and verify deposition replicated the pattern of the microwells in the PDMS mold, plasmid (pEGFP-LUC) was labeled with tetramethyl rhodamine (Label IT Nucleic Acid Labeling Kit, Mirus, Madison, WI), complexed as described above, and deposited in the microwells. After deposition, PDMS removal and rinsing, the resulting spots were visualized with fluorescence microscopy (see below).

Transfection of cells on the array was verified by depositing complexes formed with plasmid pEGFP-LUC in the microwells, as described above, and imaging with fluorescence microscopy. After complex deposition, PDMS removal and rinsing, MCF-7 cells were seeded onto the slide at a density of $10^{6}$ cells per slide $\left(18.75 \mathrm{~cm}^{2}\right)$. Transfection was analyzed after 24 and $48 \mathrm{~h}$ and characterized through GFP expression. Transfected cells were visualized using an epifluorescence microscope (Leica; Bannockburn, IL) with a FITC filter and equipped with a digital camera. Transfection, as assayed through bioluminescence imaging, was verified by depositing complexes containing both pLUC and pTKrLUC plasmids, at a 1:1 ratio. After deposition, PDMS removal and rinsing, cells were seeded as described above. Transfection was analyzed after $24 \mathrm{~h}$ and characterized by dual-luciferase expression through light emission (see below).

For induction studies in the array, complexes formed with different plasmids were immobilized in different spots of the array, in triplicate. Briefly, complexes were formed with pLUC, pERE(3×)TK-ffLUC, pERE(3×)TKffLUC and pTK-rLUC (2:1 ratio), or p $\beta$ GAL. After deposition, PDMS removal and rinsing, MCF-7 cells, which had been cultured in estrogen-free media for $18 \mathrm{~h}$, were seeded in estrogen-free medium on arrays at a density of $10^{6}$ cells per slide. Immediately after cell seeding, cells were treated with combinations $\mathrm{E}_{2}, \mathrm{FUL}$, or vehicle control, as described above. Dual-luciferase levels were analyzed $24 \mathrm{~h}$ later by bioluminescence imaging.

\section{Bioluminescence Imaging}

Expression of both luciferase reporter genes was assessed through imaging of light production upon sequential addition of the luciferase substrates to the bulk media. Bioluminescence imaging of the array was performed using an IVIS imaging system (Xenogen Corp., Alameda, CA), which utilizes a cooled CCD camera. For imaging, ViviRen (Promega), a modified renilla luciferase substrate, was diluted to $0.66 \mathrm{mM}$ in serum-containing media and then added to the arrays at a final concentration of $10 \mu \mathrm{M}$. After $2 \mathrm{~min}$, the arrays were placed into a light-tight chamber and bioluminescence images were acquired for a total exposure time of $1 \mathrm{~min}$. Immediately following imaging with ViviRen, $1 \mathrm{mM}$ D-luciferin (Molecular Therapeutics, Inc., Ann Arbor, MI, 20 mg/mL in PBS), the firefly luciferase substrate, was added into the media above the cells cultured on the array, and bioluminescence images were acquired 3 min later, with 1 min exposure. Gray scale and bioluminescence images were superimposed using the Living Image software (Xenogen Corp.). A constant size region of interest (ROI) was drawn over the spots of the array to calculate light signals. The signal intensity was reported as an integrated light flux (photons/sec), determined by IGOR software (WaveMetrics, Lake Oswego, OR). The signal due to firefly luciferase was determined by subtracting ViviRen signal from the luciferin signal. Normalization was accomplished by dividing the firefly luciferase signal (luciferin signal minus ViviRen signal, Promega) by the renilla luciferase signal (ViviRen signal). A renilla signal threshold was set at 3.5E4 photon/ sec (2X background) to distinguish spots of unreliable signals indicating insufficient transfection. 


\section{Statistics}

Statistical analysis was performed using JMP software (SAS Institute, Inc., Cary, NC). Comparative analyses were completed using one-way ANOVA with Tukey post-tests, at a 95\% confidence level. Mean values with standard deviation are reported and all experiments were performed with a minimum sample size of three, performed in replicate.

\section{Results}

\section{Multiwell Dish Format ERE-Reporter Gene Induction Studies}

Multiwell dish format reporter gene assays were performed to compare ER $\alpha$-regulated, ERE-dependent transcriptional activity in MCF-7 cells transfected via surface-mediated delivery of DNA complexes in comparison to traditional bolus delivery (Figure 1). DNA complexes, formed using an $E_{2}$-responsive firefly luciferase reporter plasmid $p E R E($ $3 \times)$ TK-ffLUC and a normalization plasmid pTK-rLUC encoding renilla luciferase, were delivered to cells via bolus or surface delivery. Transfected cells were treated with various combinations of the agonist $\mathrm{E}_{2}$, the complete antiestrogen FUL, or ethanol. Surface delivery of the plasmids (Figure $1 \mathrm{~B}$ ) resulted in $\mathrm{E}_{2}$-stimulated responses similar to bolus delivery (Figure 1A), with $\mathrm{E}_{2}$ statistically inducing firefly luciferase expression six- to sevenfold $(P<0.001)$ over vehicle control or the addition of FUL. Hence, the physio- logic state of the cells during surface-mediated delivery allowed the cells to transcriptionally respond to $E_{2}$. Further, the maximal induction of reporter gene activity was similar whether the DNA complexes were delivered via bolus or surface-mediated techniques.

The amount of transfected plasmid was subsequently investigated, which indicated a similar DNA mass-dependent effect in reporter gene activity for both surface and bolus-mediated transfection methods (Figure 2). For bolus delivery (Figure 2A), all DNA amounts resulted in significantly different responses $(P<0.01)$, except for 0.11 and $0.2 \mu \mathrm{g} / \mathrm{cm}^{2}$, which were not statistically different from each other. Maximal induction was achieved at $0.13 \mu \mathrm{g} /$ $\mathrm{cm}^{2}(0.25 \mu \mathrm{g}$ per well). For surface delivery (Figure $2 \mathrm{~B})$, all DNA amounts resulted in significantly different responses $(P<0.05)$, with $1.05 \mu \mathrm{g} / \mathrm{cm}^{2}(2 \mu \mathrm{g}$ per well $)$ corresponding to the highest induction by $\mathrm{E}_{2}$. These results indicate that sufficient amounts of DNA must be transfected for optimal reporter gene activity, and excess amounts of DNA lead to less efficient reporter gene activity, possibly due to toxicity, for both delivery methods.

Assuming that approximately $20 \%$ of DNA added to the cell culture dish surface is immobilized (Bengali et al. 2005), the condition with the highest induction $\left(1.05 \mu \mathrm{g} / \mathrm{cm}^{2}\right)$, would have presented approximately $0.21 \mu \mathrm{g} / \mathrm{cm}^{2}$ of DNA to the cells, which is higher than the bolus condition with the highest induction $\left(0.13 \mu \mathrm{g} / \mathrm{cm}^{2}\right)$, but still in the range of robust activity. Therefore, surface delivery required more DNA added to the surface than what would have been ex-
A

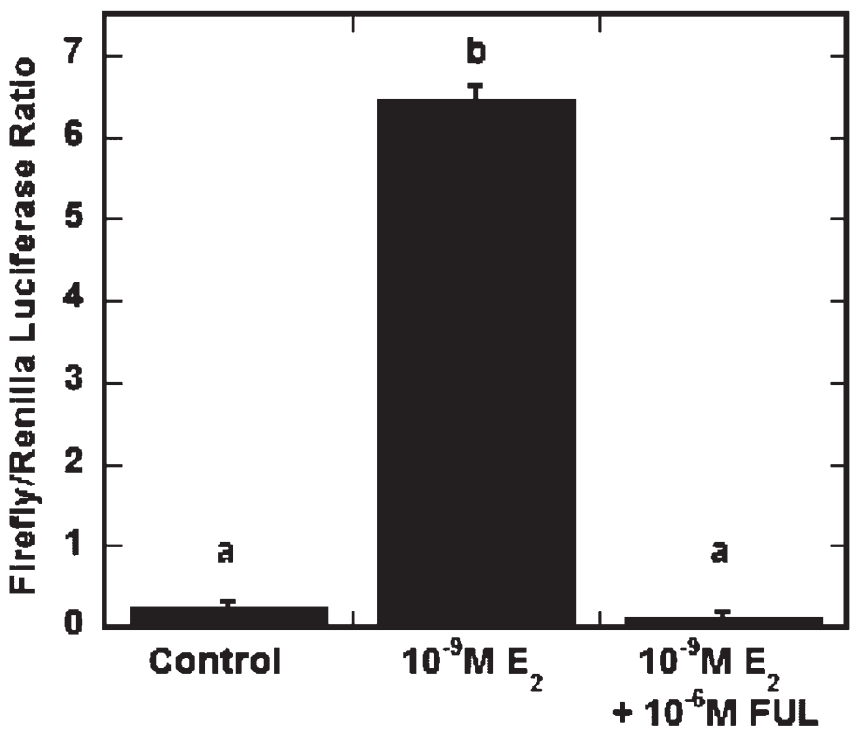

B

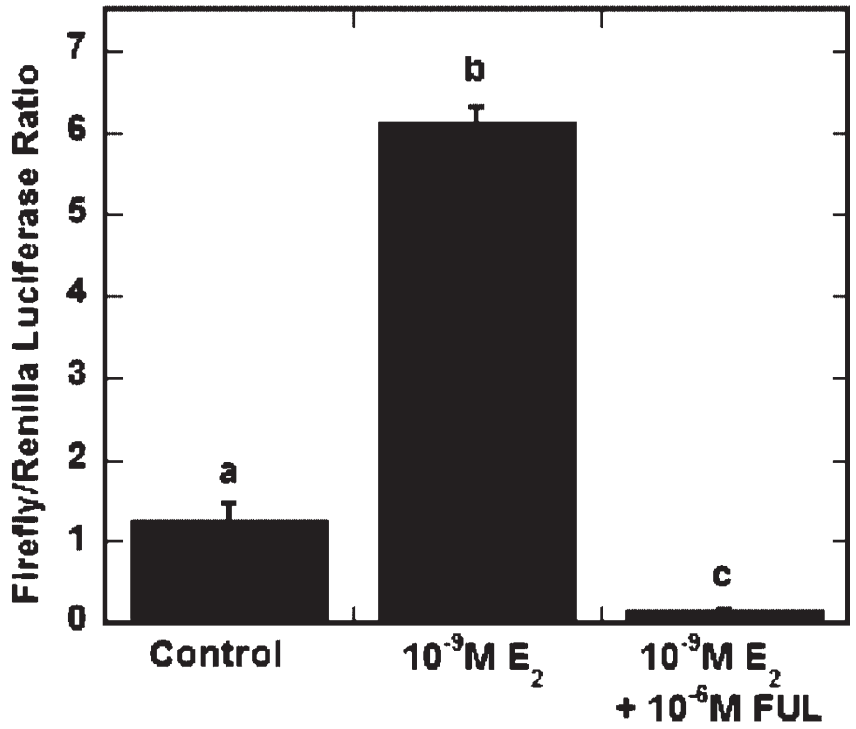

Figure 1. Multiwell dish format reporter gene assay to compare surface delivery to traditional bolus delivery. Surface delivery (B) of ERE reporter plasmid system (pERE(3×)TK-ffLUC and normalization plasmid pTK-rLUC) resulted in $\mathrm{E}_{2}$-stimulated transcriptional responses in MCF-7 breast cancer cells similar to bolus delivery $(\mathbf{A})$, reported as a ratio of firefly to renilla luciferase, with $\mathrm{E}_{2}$ statistically inducing firefly luciferase expression six- to seven-fold over vehicle control or the addition of FUL. (Columns labeled with same letter designate conditions not statistically different; all other comparisons, $P<0.001$ ). 
A

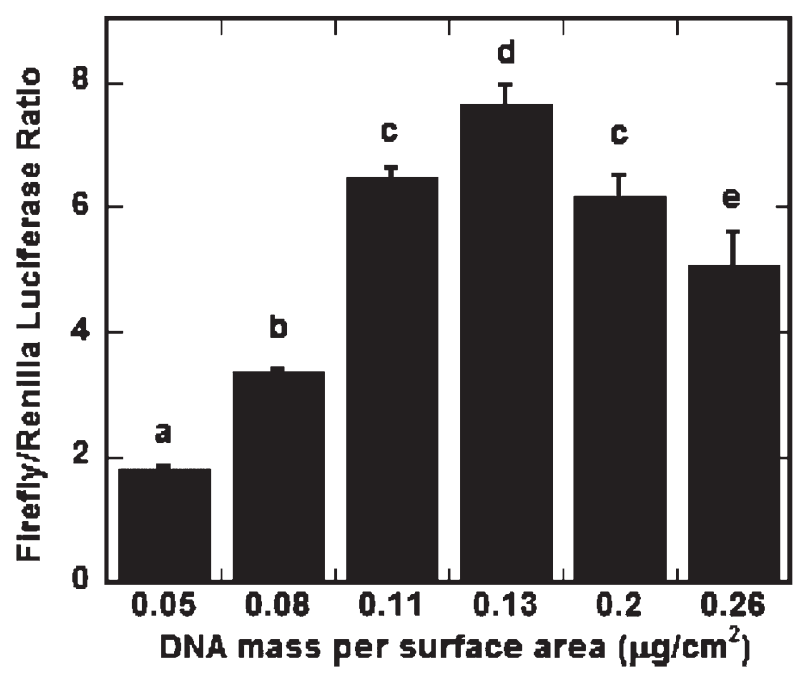

B

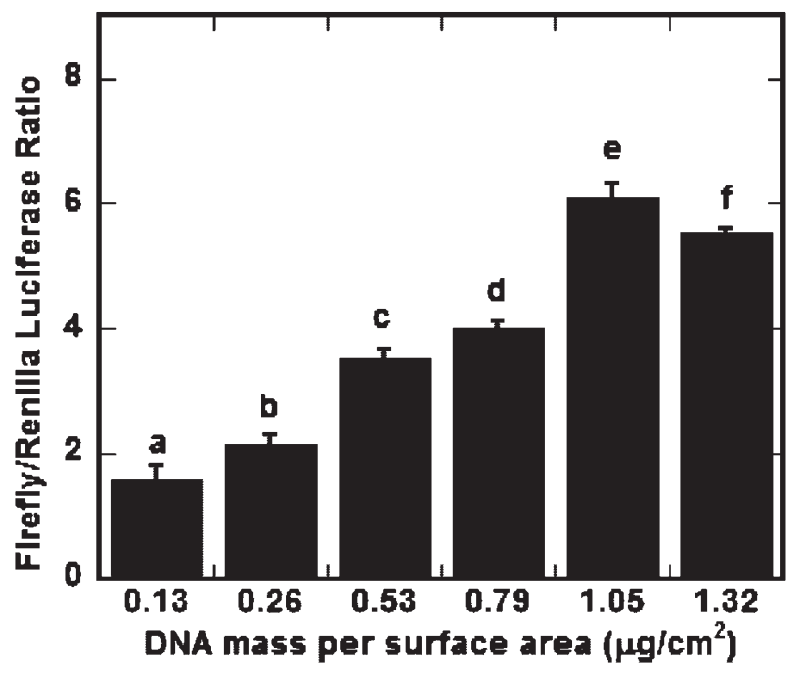

Figure 2. The effect of DNA amount on $E_{2}$ activation of ERE reporter plasmid system (pERE(3×)TK-ffLUC and normalization plasmid pTK-rLUC) delivered to MCF-7 breast cancer cells. Total amount of DNA added to the surface (B) or delivered as a bolus (A), in the presence of $10^{-9} \mathrm{M} \mathrm{E}_{2}$, resulted in a similar dose-response effect. (Columns labeled with same letter designate conditions not statistically different; all other comparisons, $\mathrm{P}<0.01$ for $(\mathrm{A}), P<0.05$ for (B).)

pected given binding profiles (Bengali et al. 2005). The requirement for more DNA may be due to lower than anticipated binding efficiencies $(\sim 10 \%$, but still within the range of profiles reported).

The specific transfection reagent used to form DNA complexes, and $\mathrm{E}_{2}$ concentration responses were subsequently investigated to determine the applicability and sensitivity of the reporter system (Figure 3). For Lipofectamine 2000DNA complexes (Figure 3A), $\mathrm{E}_{2}$-induction profiles were not significantly different using bolus versus surface delivery (Figure $3 \mathrm{~A}$ ), with $\mathrm{E}_{2}$ eliciting a concentration response from $10^{-12}$ to $10^{-10} \mathrm{M}(P<0.05)$, and maximal responsiveness observed from $10^{-10}$ to $10^{-9} \mathrm{M} \mathrm{E}_{2}(P>0.05)$ for both delivery methods. For Effectene complexes (Figure 3B), bolus delivery resulted in statistically higher levels of ERE induction $(P<0.05)$ than surface delivery for all concentrations of $E_{2}$, except control. However, the level of ERE induction for surface-mediated delivery was similar whether
A

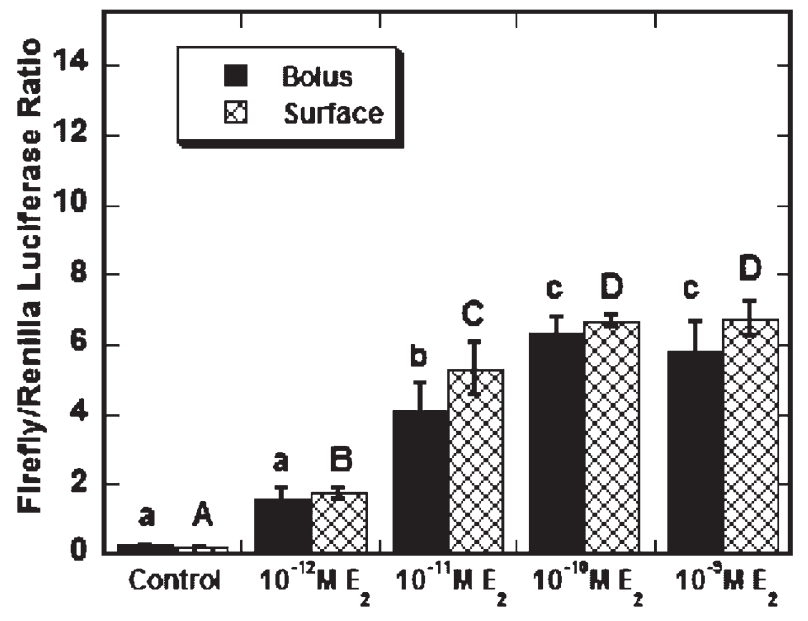

B

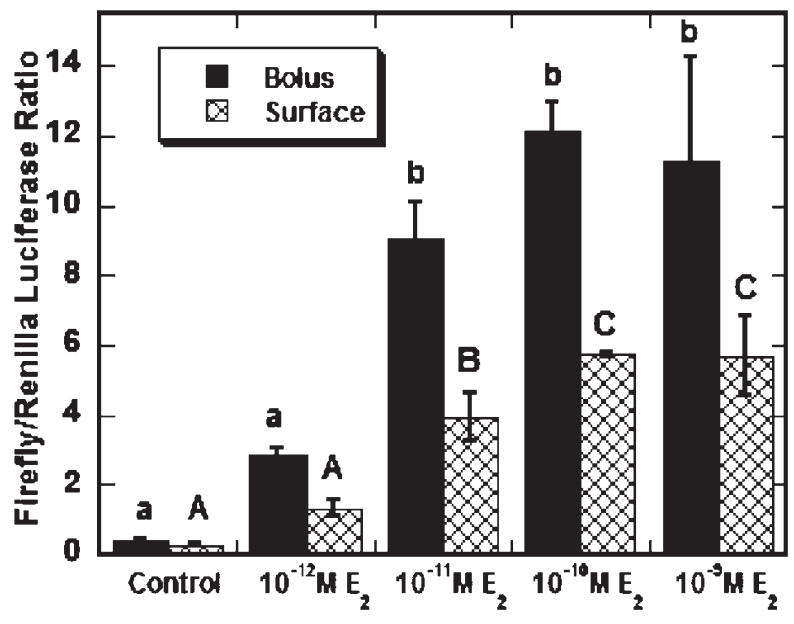

Figure 3. The effect of complexing agent and $\mathrm{E}_{2}$ dose response on the ERE reporter plasmid system (pERE(3×)TK-ffLUC and normalization plasmid pTK-rLUC). Bolus and surface delivery of Lipofectamine 2000 complexes (A) resulted in induction profiles that were not statistically different from each other, for each concentration of $E_{2}$. Bolus delivery of Effectene complexes (B) resulted in statistically higher induction $(P<0.05)$ than surface delivery for all concentrations of $\mathrm{E}_{2}$, except control, however surface delivery resulted in more statistically different induction responses. (Columns labeled with same letter designate conditions are not statistically different; all other comparisons, $P<0.05$.) 
complexing DNA with Effectene (Figure 3B) or with Lipofectamine 2000 (Figure 2A). Therefore, the particular transfection reagent used affected transcriptional activity via the conventional bolus delivery, but not via surface delivery. None the less, these results demonstrate that either Effectene or Lipofectamine 2000 can be used to delivery plasmid via surface-mediated transfection. Further, other transfection reagents can likely be adapted for use in surface-mediated delivery.

\section{Array Fabrication and Verification}

An array was created using soft lithography techniques to pattern DNA-lipid complex deposition and subsequent transfection upon cell seeding (Figure 4). Briefly, a PDMS mold with microwells (Figure 4A) was reversibly sealed to polystyrene microscope slides (Figure 4B), with the microwells serving as reservoirs for deposition of DNA complexes onto the polystyrene slide (Figure $4 \mathrm{C}$ ). Rhodaminelabeled DNA complexes deposited within microwells were immobilized to the slide in distinct regions, replicating the pattern of microwells in the PDMS mold (Figure 4DF). Transfection of MCF-7 cells seeded onto arrays of complexes was determined by GFP expression, and was also confined to the patterns (Figure 4G-I).

\section{Bioluminescence Imaging of the Array}

Arrays formed with complexes containing plasmids encoding firefly and renilla luciferase reporter genes (pLUC and pTK-rLUC) were used to verify the ability of bioluminescence imaging to detect dual-luciferase expression (Figure 5). Transfection of MCF-7 cells seeded onto these arrays was assayed after $24 \mathrm{~h}$ by sequentially adding the renilla and firefly luciferase substrates. Following ViviRen addition, spot intensities averaged $1.10 \times 10^{5} \pm 2.56 \times 10^{4}$ photon $/ \mathrm{sec}$ (Figure 5A), which are similar to signals obtained with arrays of only pTK-rLUC plasmid (data not shown). D-Luciferin was subsequently added to the same array, which was then imaged to acquire a dual signal (Figure 5B), with average spot intensities of $3.66 \times 10^{6} \pm 4.34 \times 10^{5} \mathrm{photon} / \mathrm{sec}$. Firefly luciferase expression was determined by subtracting the initial ViviRen signal from the signal obtained through imaging with the D-luciferin. Firefly expression averaged $3.55 \times 10^{6} \pm 4.30 \times 10^{5} \mathrm{photon} / \mathrm{sec}$, also similar to intensities obtained with arrays formed with only pLUC plasmid (data not shown). After normalization, the firefly luciferase signal was $34 \pm 8$ fold greater than the respective renilla expression. Timecourse studies revealed that the ViviRen signal remained constant for $10 \mathrm{~min}$ after substrate addition. Therefore the firefly luciferase signal could be obtained using this dual imaging strategy followed by subtraction techniques, given imaging was accomplished within $10 \mathrm{~min}$ of ViviRen addition (data not shown). Bioluminescence imaging was able to sensitively capture both luciferase signals, enabling the same cell population to be analyzed for the expression of multiple reporter genes.

\section{Array Format ERE-Reporter Gene Induction Studies}

To assess the ability of the arrays to monitor induction of ER $\alpha$ transcriptional activity (Figure 6), complexes formed with different plasmids were immobilized as an array in triplicates as follows: 1 . pLUC, 2. no DNA (mock), 3. pERE(3×)TK-ffLUC, 4. pERE(3×)TK-ffLUC and pTKrLUC (2:1 ratio), and 5. p $\beta$ GAL. Cells seeded on the arrays were treated with combinations of ethanol control (Figure 6A,B), $10^{-9} \mathrm{M} \mathrm{E}_{2}$ (Figure $6 \mathrm{C}, \mathrm{D}$ ), or $10^{-9} \mathrm{M} \mathrm{E}_{2}+10^{-6}$ MFUL (Figure $6 \mathrm{E}, \mathrm{F})$. Dual-luciferase levels were analyzed $24 \mathrm{~h}$ later using

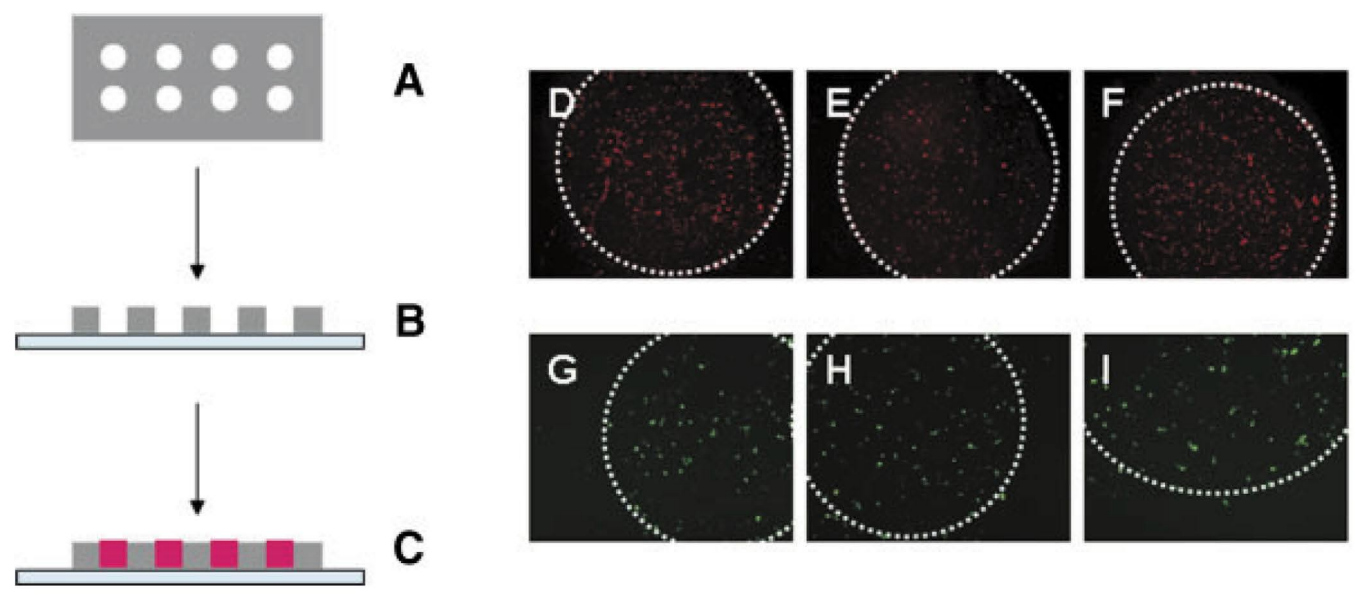

Figure 4. Array fabrication with soft lithography techniques to pattern DNA-lipid complex deposition and transfection. A polydimethylsiloxane (PDMS) mold (A) was reversibly sealed to polystyrene slides (B), so that the holes in the mold, termed microwells, served as reservoirs for deposition of DNA complexes onto the polystyrene (C). After complex deposition in the microwells, the PDMS mold was peeled away from the polystyrene slide, which was then rinsed thoroughly. Rhodamine-labeled DNA complexes were immobilized on the slide in distinct regions, replicating the pattern of microwells in the PDMS mold (D-F). Transfection of MCF-7 cells seeded onto these arrays of patterned complexes on polystyrene slides was also confined to the patterns, as determined by GFP expression (G-I). 

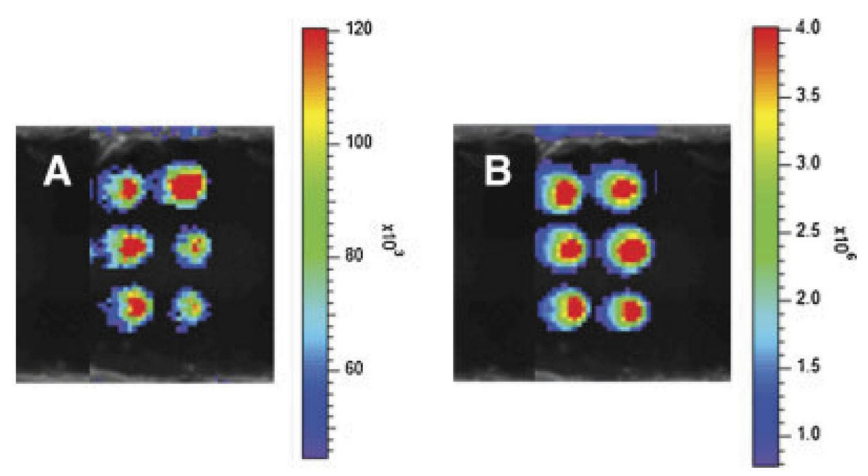

Figure 5. Bioluminescence imaging to detect dual-luciferase expression in an array format. Transfection of MCF-7 cells seeded onto arrays of complexes was assayed after $24 \mathrm{~h}$ by sequentially adding the renilla and firefly luciferase substrates. The renilla substrate, ViviRen $(10 \mu \mathrm{M})$, was first added into the media and the array was imaged to determine pTK-rLUC expression (A). D-Luciferin (1 mM) was subsequently added to the same array, which was then imaged to acquire a dual signal (B). Firefly luciferase expression (pLUC) was determined by subtracting the ViviRen signal from the signal obtained through imaging with the D-luciferin. When normalized, the firefly luciferase signal was $34 \pm 8$ fold greater than the respective renilla expression.

bioluminescence imaging, by first imaging with ViviRen (Figure 6A,C,E), and then imaging each array with D-luciferin (Figure 6B,E,F). Renilla luciferase activity was only detected in cells transfected with pTK-rLUC plasmid (Figure $6 \mathrm{~A}, \mathrm{C}, \mathrm{E}$, column 4), and not in cells transfected with only firefly luciferase-encoding plasmids (Figure 6A,C,E, columns 1 and 3), a control $\beta$ GAL-encoding plasmid (Figure $6 \mathrm{~A}, \mathrm{C}, \mathrm{E}$, column 5) or no DNA (Figure 6A,C,E, column 2). Accordingly, firefly luciferase activity was only detected in cells transfected with pLUC (Figure 6B,D,F, column 1) or pERE( $3 \times)$ TK-ffLUC (Figure 6B,D,F, columns 3 and 4), but not in mock or $\beta$ GAL control transfected cells (Figure $6 \mathrm{~B}, \mathrm{D}, \mathrm{F}$, columns 2 and 5) These results verify the specificity of renilla and firefly luciferase detection in this system.

As predicted, firefly luciferase activity was detected at substantially higher levels in cells transfected with pERE( $3 \times$ )TK-ffLUC and treated with $\mathrm{E}_{2}$ (Figure 6D, columns 3 and 4) compared to those treated with ethanol (Figure $6 \mathrm{~B}$, columns 3 and 4 ) or $\mathrm{E}_{2}+\mathrm{FUL}$ (Figure $6 \mathrm{~F}$, columns 3 and 4 ). In control-treated arrays, spots of highest intensity were visualized for pLUC (Figure 6B, column 1), given its highly active CMV promoter. Cells transfected with both the pERE(3×)TK-ffLUC and pTK-rLUC plasmids (Figure $6 \mathrm{~B}$, column 4) resulted in higher signal intensities in the presence of luciferin than cells transfected with only the pERE(3x)TK-ffLUC (Figure 6B, column 3), as there was no carryover of ViviRen signal in the latter spots of transfected cells without pTK-rLUC. For $\mathrm{E}_{2}$ addition to the array, signal intensities with luciferin increased as compared to the control condition for all cells transfected with pERE(3×)TKffLUC plasmids (Figure 6D, columns 3 and 4), indicating ER $\alpha$-dependent transcriptional activation of the ERE-regu- lated plasmid. Expression of the pLUC plasmid was largely unaffected by $\mathrm{E}_{2}$ (Figure 6D, column 1). Addition of the antiestrogen FUL to the arrays completely eliminated the signal in cells transfected with pERE(3x)TK-ffLUC alone (Figure 6F, column 3), or substantially reduced signal intensities in cells transfected with both pERE(3x)TK-ffLUC and pTK-rLUC (Figure 6F, column 4), in which the luminescence that was detected was again due to carryover of the ViviRen signal. Therefore, addition of $10^{-6} \mathrm{M}$ FUL led to a complete blockade of ER $\alpha$-stimulated activity by $10^{-9}$ $\mathrm{ME}_{2}$. pLUC expression was also lowered in the presence of FUL (Figure 6F, column 1) indicating that some transcriptional elements in the CMV may be indirectly regulated by $\mathrm{ER} \alpha$, possibly by ER $\alpha$ tethering to AP1 and SP1 proteins bound directly to DNA in this promoter.

Average renilla luminescence intensities in cells transfected with pERE(3x)TK-ffLUC and pTK-rLUC plasmids (Figure 6A,C,E, column 4) were similar in control and $\mathrm{E}_{2}+$ FUL treated cells, but lower in $\mathrm{E}_{2}$ alone treated cells. This lower renilla luciferase activity is likely due to competition for transcriptional cofactors between the $\operatorname{ERE}(3 \times) \mathrm{TK}$ and TK-only regulated promoters. Under $\mathrm{E}_{2}$ stimulation conditions, ER $\alpha$ transcriptional coregulators and basal transcriptional machinery may be preferentially recruited to EREcontaining promoters rather than promoters lacking EREs. Hence, in cells treated with $\mathrm{E}_{2}$, squelching likely occurs at the TK-renilla luciferase promoter due to titrating out of limiting transcription factors.

Induction of the ER-regulated plasmid system in the array mimicked results obtained through traditional assays methods. Firefly luciferase expression was determined by subtracting the ViviRen signal from the signal obtained through imaging with the D-luciferin, which was then normalized by the ViviRen signal (Figure 6G). For cells transfected with both the pERE(3×)TK-ffLUC and pTKrLUC plasmids (Figure 6, column 4), $E_{2}$ statistically induced dual-luciferase activity 10 -fold $(P<0.001)$ over control or FUL conditions (Figure 6G). This robust induction verifies that the array can accurately report on the activity of the $\mathrm{ER} \alpha$ transcription factor. The concentration response of $\mathrm{E}_{2}$ was examined to determine the sensitivity of the reporter system in an array format (Figure 7). For arrays with spots containing both the pERE(3x)TK-ffLUC and pTK-rLUC plasmids, increasing the concentration of $E_{2}$ statistically increased the induction of firefly luciferase expression $(P<$ $0.05)$, capturing the concentration-response of $E_{2}$ in the induction of this plasmid system.

\section{Discussion}

Methods to use mammalian cells as suitable screening systems need to be developed to elucidate gene function and cellular pathways responsible for diseases (Grimm, 2004). Transfected cell arrays offer an advantage in their ability to analyze the expression of genes and the function of proteins in living cells, where the machinery is present to ensure correct function of the gene products. These live cell 


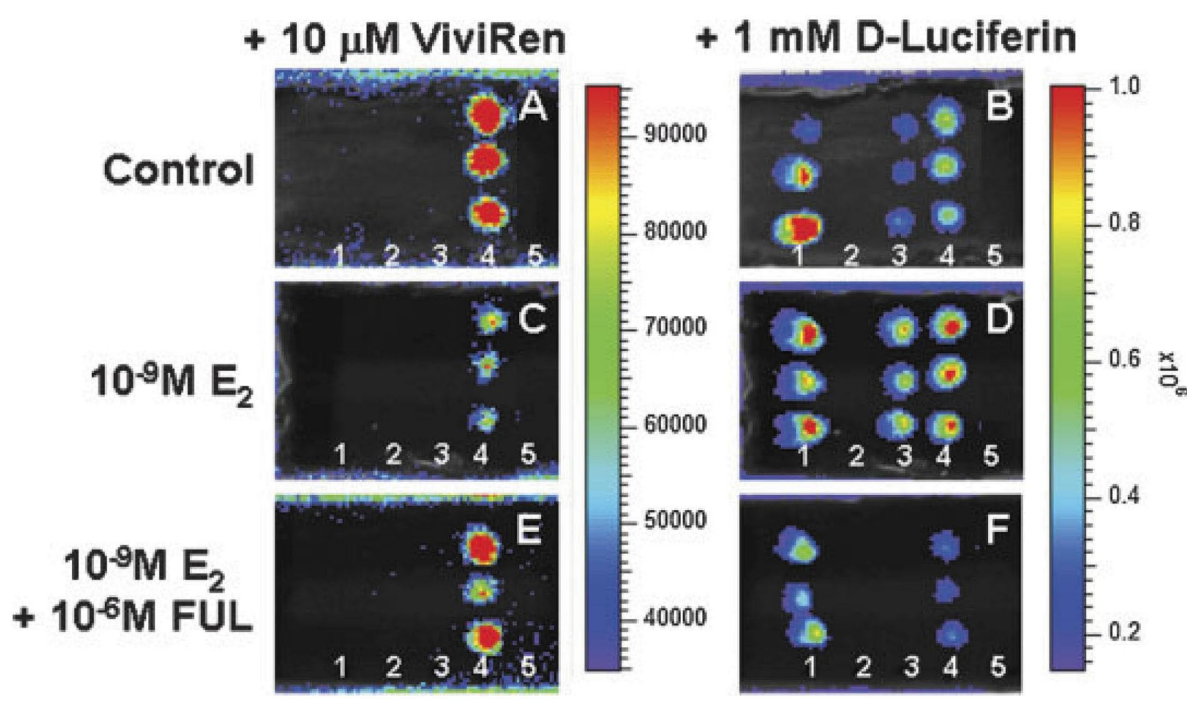

\section{G}

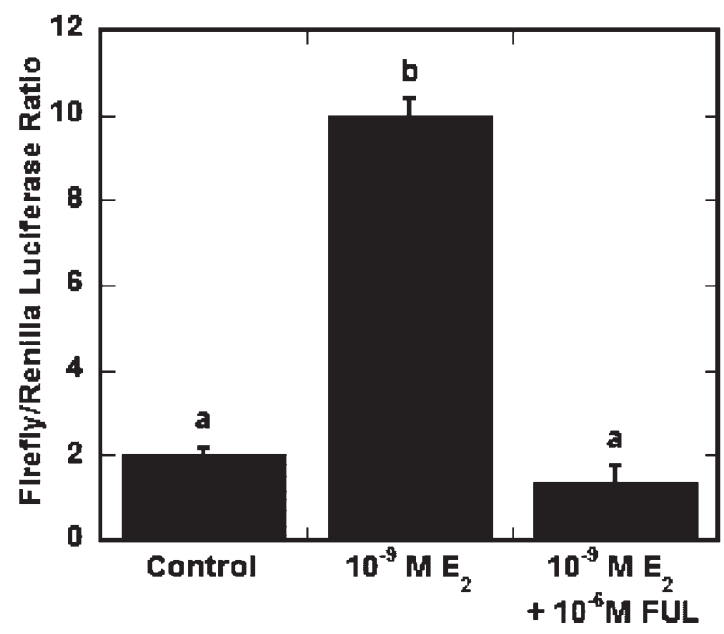

Figure 6. Arrays to monitor ER $\alpha$ induction of transcriptional activity. Complexes formed with different plasmids were immobilized in different spots of the array, in triplicate, as follows: (1) pLUC, (2) none, (3) pERE(3×)TK-ffLUC, (4) pERE(3×)TK-ffLUC and pTK-rLUC (2:1 ratio), and (5) p $\beta$ GAL. Cells seeded on the arrays were treated with combinations of ethanol control (A,B), $E_{2}$ $(\mathbf{C}, \mathbf{D})$, or $\mathrm{E}_{2}+\mathrm{FUL}(\mathrm{E}, \mathrm{F})$. Dual-luciferase levels were analyzed $24 \mathrm{~h}$ later with bioluminescence imaging, by first imaging with the renilla luciferase substrate, ViviRen $(A, C, E)$ and then imaging each array with D-luciferin, the firefly luciferase substrate (B,E,F). Induction of the ERE-regulated plasmid system was calculated by normalizing firefly luciferase expression to renilla luciferase expression (G). Firefly luciferase expression was determined by subtracting the ViviRen signal from the signal obtained through imaging with the D-luciferin. For spots containing both the pERE(3×)TK-ffLUC and pTK-rLUC plasmids (column 4), $\mathrm{E}_{2}$ statistically induced firefly luciferase expression 10-fold over control or FUL conditions, reported as a ratio of firefly to renilla luciferase (G). (Columns labeled with same letter designate conditions that are not statistically different; all other comparisons, $P<0.001$.)

microarrays could provide a method to link gene expression to functional cell responses, with the potential to impact many aspects of science and medicine. Transfected cell arrays have been primarily used for identification of gene function (Hodges et al., 2005) and discovery of novel genes and proteins (Ziauddin and Sabatini, 2001), and have potential utility in emerging applications such as detection of biological warfare agents and environmental toxins through surface receptors (Delehanty et al., 2004b), detection of tumor-associated antigens (Hoeben et al., 2006), and determination of molecular markers or targets (Palmer and Freeman, 2005), prior to the costly develop- ment of novel diagnostic and therapeutic strategies. With many possible applications for transfected cell arrays, technological advances are needed to improve array accuracy and consistency and to facilitate endpoint analysis (Hook et al., 2006; Palmer and Freeman, 2005). We have combined dual plasmid delivery and bioluminescence imaging to create a transfected cell array that allows for normalization of transfection, and provides rapid and sensitive quantification of the cellular response with minimal post-transfection processing.

In our transfected cell array, we employed a dual plasmid system to provide normalization, sensitivity, and 


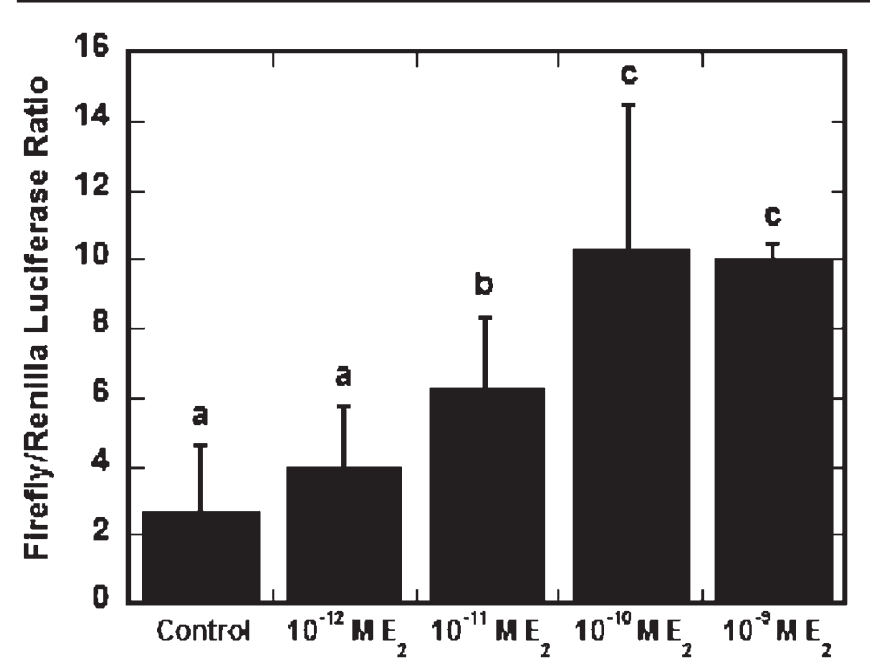

Figure 7. Concentration response of $\mathrm{E}_{2}$ on the ERE reporter plasmid system in an array format. For spots containing both the pERE(3×)TK-ffLUC and pTK-rLUC plasmids, increasing the concentration of $E_{2}$ statistically increased the induction of firefly luciferase expression, verifying a true concentration-response of $E_{2}$ in the induction of this plasmid system in an array format. (Columns labeled with same letter designate conditions that are not statistically different; all other comparisons, $P<0.05$.)

quantification, which are all intricately related, in part, through the transfection efficiency. Spot to spot variability in transfection can compromise the ability to quantify a response within an array, as sub-maximal responses may indicate either a limited effect or simply inefficient or unequal delivery. A variance in fluorescence intensity of transfected cells (GFP) has been noted between spots of the array, which likely correlates with the number of plasmids internalized (Hook et al., 2006). Therefore, to enable normalization of transfection efficiency, a two-plasmid system consisting of: (i) a normalization plasmid that is present within each spot, and (ii) a functional plasmid that varies between spots and is responsible for the functional endpoint of the array, was deposited in each spot. Both plasmids contain the same TK promoter, which is important for normalization, and should allow comparison between cell lines on the array. Delivery of two plasmids has been shown to result in a majority of cells expressing both reporter genes (unpublished observations). To normalize with a second plasmid, the efficiency of delivery must be sufficient to obtain a signal from each plasmid. This issue was addressed using larger spot sizes relative to many previous reports. Small spot size can contribute to low transfection efficiencies (Palmer and Freeman, 2005), which are detrimental because each spot on the array may contain so few cells that an insufficient number of cells are transfected locally to be statistically informative (Hodges et al., 2005). Small spots with low transfection efficiency make image acquisition and quantification difficult and lower sensitivity, which can lead to high false positive and false negative rates (Palmer et al., 2006), further demonstrating a need to account for efficiency and normalization issues to increase the reliability of quantitative data obtained from each spot (Fujimoto et al., 2006). To further address issues with transfection efficiency, our array fabrication and normalization approach could be compatible with viral delivery (Bailey et al., 2006; Hobson et al., 2003; Michiels et al., 2002), however a plasmid system is more versatile due to the easier production and handling methods.

Bioluminescence imaging (Rutter et al., 1998) was employed to quantify the response of the dual plasmids within the array, with minimal post-transfection processing and high sensitivity. Endpoint analysis for the arrays often requires tagging or staining (Hook et al., 2006) to report gene function, which can require extensive post-transfection processing, such as fixation and immunostaining (Lee et al., 2006; Wheeler et al., 2005). The normalization and functional plasmids contain renilla and firefly luciferase reporters respectively, which can both be rapidly quantified in each spot by sequential addition of the respective substrates to the culture media followed by imaging of the array. Luciferase reporters are known to be more sensitive than GFP, without the issues of autofluorescence and background signals (Rutter et al., 1998). Luciferase is more quantitative and allows for small differences in expression to be determined, which enabled our system to determine a dose response to an external stimulus. An additional potential advantage, the short half-life of luciferase could allow for real-time imaging to follow the dynamics of gene activity (Rutter et al., 1998). However, alternative imaging systems requiring automated microscopy and image processing (Pepperkok and Ellenberg, 2006; Wheeler et al., 2005) can allow for detection of changes in cellular morphology and cellular level data, which is not possible with bioluminescence imaging.

The array was used to quantify the activity of the ER $\alpha$ in breast cancer cells with an ERE-regulated promoter reporter system, as an example of an inducible plasmid system in a cancer model. ER $\alpha$, a member of the nuclear receptor superfamily of transcription factors, activates transcription through binding of its ligand, $\mathrm{E}_{2}$. Expression of ER $\alpha$ is clinically used as a biomarker to determine treatment for breast cancer patients (Ariazi et al., 2006; Pearce and Jordan, 2004). However, simple expression of transcription factors like ER $\alpha$ does not necessarily reflect pathway activation, as transcription factor activity is regulated through diverse mechanisms (Levine and Tjian, 2003), including heteromeric complexes, ubiquitination, methylation, acetylation, and post-translational modifications such as phosphorylation. The transfected cell array allows for the determination of transcription factor activity. In the case of the $E R \alpha$, we assayed for induction by $E_{2}$. Induction in the array mimicked results obtained through traditional luciferase assay methods, with $\mathrm{E}_{2}$ inducing luciferase expression 10-fold over fulvestrant or vehicle controls. The array also captured the varying ER activity in response to a range of $\mathrm{E}_{2}$ dosages, further demonstrating the sensitivity of the bioluminescence quantification system.

In summary, this report demonstrates the ability to quantitatively assess a transfected cell array using dual bio- 
luminescence imaging to enable normalization of transfection efficiency, while reducing post-transfection processing and increasing sensitivity. Additionally, ER activity was quantified in a physiologically relevant model of breast cancer, indicating the effectiveness of the array system, as many of the published arrays have only used HEK293T cells, a cell line known to be easily transfected and not applicable to many relevant biological endpoints or applications. The dual plasmid system and bioluminescence imaging are enabling technologies that, when combined with high-throughput arrays involving large numbers of plasmids, have the potential to impact basic research in cancer and other disciplines through investigation of fundamental biological processes (Hoeben et al., 2006). With further advancements in the transfection of primary cells, transfected cell arrays have the potential for use in cancer medicine, to classify clinical cancer samples through prognostic profiles (Chen and Davis, 2006), to provide novel information regarding disease progression, and to identify molecular targets for patient-specific therapy (Kozarova et al., 2006).

\section{Acknowledgments}

Support for this research was provided in part by grants from NIH (RO1 GM066830) to LDS, CMBD Training Grant to AKP, and P50 CA 89018 (Specialized Program of Research Excellence in Breast Cancer) to VCJ, and NSF (Graduate Research Fellowship to AKP). We would like to thank Dr. Bill Lowe, Dr. Dixon Kaufman, Dr. Phil Messersmith, Courtney Larsen, and Robert Rayson for equipment use and technical assistance.

\section{References}

Ariazi EA, Ariazi JL, Cordera F, Jordan VC. 2006. Estrogen receptors as therapeutic targets in breast cancer. Curr Top Med Chem 6(3):181-202.

Bailey SN, Ali SM, Carpenter AE, Higgins CO, Sabatini DM. 2006. Microarrays of lentiviruses for gene function screens in immortalized and primary cells. Nat Methods 3(2):117-122.

Bengali Z, Pannier AK, Segura T, Anderson BC, Jang JH, Mustoe TA, Shea LD. 2005. Gene delivery through cell culture substrate adsorbed DNA complexes. Biotechnol Bioeng 90(3):290-302.

Catherino WH, Jordan VC. 1995. Increasing the number of tandem estrogen response elements increases the estrogenic activity of a tamoxifen analogue. Cancer Lett 92(1):39-47.

Chang FH, Lee CH, Chen MT, Kuo CC, Chiang YL, Hang CY, Roffler S. 2004. Surfection: A new platform for transfected cell arrays. Nucleic Acids Res 32(3):e33.

Chen DS, Davis MM. 2006. Molecular and functional analysis using live cell microarrays. Curr Opin Chem Biol 10(1):28-34.

Delehanty JB, Shaffer KM, Lin B. 2004a. A comparison of microscope slide substrates for use in transfected cell microarrays. Biosens Bioelectron 20(4):773-779.

Delehanty JB, Shaffer KM, Lin B. 2004b. Transfected cell microarrays for the expression of membrane-displayed single-chain antibodies. Anal Chem 76(24):7323-7328.
Erfle H, Simpson JC, Bastiaens PI, Pepperkok R. 2004. siRNA cell arrays for high-content screening microscopy. Biotechniques 37(3):454-458, 460, 462.

Fujimoto H, Yoshizako S, Kato K, Iwata H. 2006. Fabrication of cell-based arrays using micropatterned alkanethiol monolayers for the parallel silencing of specific genes by small interfering RNA. Bioconjug Chem 17(6):1404-1410.

Grimm S. 2004. The art and design of genetic screens: Mammalian culture cells. Nat Rev Genet 5(3):179-189.

Hobson DA, Pandori MW, Sano T. 2003. In situ transduction of target cells on solid surfaces by immobilized viral vectors. BMC Biotechnol 3(1):4.

Hodges E, Redelius JS, Wu W, Hoog C. 2005. Accelerated discovery of novel protein function in cultured human cells. Mol Cell Proteomics 4(9):1319-1327.

Hoeben A, Landuyt B, Botrus G, De Boeck G, Guetens G, Highly M, van Oosterom AT, de Bruijn EA. 2006. Proteomics in cancer research: Methods and application of array-based protein profiling technologies. Analytica Chimica Acta 564(1):19-33.

Honma K, Ochiya T, Nagahara S, Sano A, Yamamoto H, Hirai K, Aso Y, Terada M. 2001. Atelocollagen-based gene transfer in cells allows high-throughput screening of gene functions. Biochem Biophys Res Commun 289(5):1075-1081.

Hook AL, Thissen H, Voelcker NH. 2006. Surface manipulation of biomolecules for cell microarray applications. Trends Biotechnol 24(10):471-477.

How SE, Yingyongnarongkul B, Fara MA, Diaz-Mochon JJ, Mittoo S, Bradley M. 2004. Polyplexes and lipoplexes for mammalian gene delivery: From traditional to microarray screening. Comb Chem High Throughput Screen 7(5):423-430.

Hu YH, Vanhecke D, Lehrach H, Janitz M. 2005. High-throughput subcellular protein localization using cell arrays. Biochem Soc Trans 33(Pt 6):1407-1408.

Hu YH, Warnatz HJ, Vanhecke D, Wagner F, Fiebitz A, Thamm S, Kahlem P, Lehrach H, Yaspo ML, Janitz M. 2006. Cell array-based intracellular localization screening reveals novel functional features of human chromosome 21 proteins. BMC Genomics 7:155.

Ikeda K, Inoue S. 2004. Estrogen receptors and their downstream targets in cancer. Arch Histol Cytol 67(5):435-442.

Isalan M, Santori MI, Gonzalez C, Serrano L. 2005. Localized transfection on arrays of magnetic beads coated with PCR products. Nat Methods 2(2):113-118.

Jiang SY, Wolf DM, Yingling JM, Chang C, Jordan VC. 1992. An estrogen receptor positive MCF-7 clone that is resistant to antiestrogens and estradiol. Mol Cell Endocrinol 90(1):77-86.

Kato K, Umezawa K, Miyake M, Miyake J, Nagamune T. 2004. Transfection microarray of nonadherent cells on an oleyl poly(ethylene glycol) ether-modified glass slide. Biotechniques 37(3):444-448, 450, 452.

Kozarova A, Petrinac S, Ali A, Hudson JW. 2006. Array of informatics: Applications in modern research. J Proteome Res 5(5):1051- 1059.

Lee CW, Rivera R, Gardell S, Dubin AE, Chun J. 2006. GPR92 as a new G12/13- and Gq-coupled lysophosphatidic acid receptor that increases cAMP, L PA5. J Biol Chem 281(33):23589-23597. 
Levenson AS, Jordan VC. 1997. MCF-7: The first hormone-responsive breast cancer cell line. Cancer Res 57(15):3071-3078.

Levine M, Tjian R. 2003. Transcription regulation and animal diversity. Nature 424(6945):147-151.

Mannherz O, Mertens D, Hahn M, Lichter P. 2006. Functional screening for proapoptotic genes by reverse transfection cell array technology. Genomics 87(5):665-672.

Michiels F, van Es H, van Rompaey L, Merchiers P, Francken B, Pittois K, van der Schueren J, Brys R, Vandersmissen J, Beirinckx F, et al. 2002. Arrayed adenoviral expression libraries for functional screening. Nat Biotechnol 20(11):1154-1157.

Mousses S, Caplen NJ, Cornelison R, Weaver D, Basik M, Hautaniemi S, Elkahloun AG, Lotufo RA, Choudary A, Dougherty ER, et al. 2003. RNAi microarray analysis in cultured mammalian cells. Genome Res 13(10):2341-2347.

Neumann B, Held M, Liebel U, Erfle H, Rogers P, Pepperkok R, Ellenberg J. 2006. High-throughput RNAi screening by time-lapse imaging of live human cells. Nat Methods 3(5):385-390.

Palmer E, Freeman T. 2005. Cell-based microarrays: Current progress, future prospects. Pharmacogenomics 6(5):527-534.

Palmer EL, Miller AD, Freeman TC. 2006. Identification and characterisation of human apoptosis inducing proteins using cell-based transfection microarrays and expression analysis. BMC Genomics 7(1):145.

Pannier AK, Anderson BC, Shea LD. 2005. Substrate-mediated delivery from self-assembled monolayers: Effect of surface ionization, hydrophilicity, and patterning. Acta Biomaterialia 1(5):511- 522.

Pearce ST, Jordan VC. 2004. The biological role of estrogen receptors alpha and beta in cancer. Crit Rev Oncol Hematol 50(1):3-22.

Pepperkok R, Ellenberg J. 2006. High-throughput fluorescence microscopy for systems biology. Nat Rev Mol Cell Biol 7(9):690-696.

Peterbauer T, Heitz J, Olbrich M, Hering S. 2006. Simple and versatile methods for the fabrication of arrays of live mammalian cells. Lab Chip 6(7):857-863.

Pichler A, Zelcer N, Prior JL, Kuil AJ, Piwnica-Worms D. 2005. In vivo RNA interference-mediated ablation of MDR1 Pglycoprotein. Clin Cancer Res 11(12):4487-4494.

Rafiq I, Kennedy HJ, Rutter GA. 1998. Glucose-dependent translocation of insulin promoter factor-1 (IPF-1) between the nuclear periphery and the nucleoplasm of single MIN6 beta-cells. J Biol Chem 273(36):23241- 23247.
Redmond TM, Ren X, Kubish G, Atkins S, Low S, Uhler MD. 2004. Microarray transfection analysis of transcriptional regulation by cAMP-dependent protein kinase. Mol Cell Proteomics 3(8):770- 779.

Rutter GA, Kennedy HJ, Wood CD, White MR, Tavare JM. 1998. Real-time imaging of gene expression in single living cells. Chem Biol 5(11): R285-R290.

Segura T, Shea LD. 2002. Surface-tethered DNA complexes for enhanced gene delivery. Bioconjug Chem 13(3):621-629.

Segura T, Volk MJ, Shea LD. 2003. Substrate-mediated DNA delivery: Role of the cationic polymer structure and extent of modification. J Control Release 93(1):69-84.

Silva JM, Mizuno H, Brady A, Lucito R, Hannon GJ. 2004. RNA interference microarrays: High-throughput loss-offunction genetics in mammalian cells. Proc Natl Acad Sci USA 101(17):6548-6552.

Webb BL, Diaz B, Martin GS, Lai F. 2003. A reporter system for reverse transfection cell arrays. J Biomol Screen 8(6):620-623.

Wheeler DB, Bailey SN, Guertin DA, Carpenter AE, Higgins CO, Sabatini DM. 2004. RNAi living-cell microarrays for loss-of-function screens in Drosophila melanogaster cells. Nat Methods 1(2):127-132.

Wheeler DB, Carpenter AE, Sabatini DM. 2005. Cell microarrays and RNA interference chip away at gene function. Nat Genet 37(Suppl): S25-S30.

Xia Y, Whitesides GM. 1998. Soft lithography. Angew Chem Int Ed 37:550- 575.

Yamauchi F, Kato K, Iwata H. 2004a. Micropatterned, self-assembled monolayers for fabrication of transfected cell microarrays. Biochim Biophys Acta 1672(3):138-147.

Yamauchi F, Kato K, Iwata H. 2004b. Spatially and temporally controlled gene transfer by electroporation into adherent cells on plasmid DNA-loaded electrodes. Nucleic Acids Res 32(22):e187.

Yamauchi F, Kato K, Iwata H. 2005. Layer-by-layer assembly of poly- (ethyleneimine) and plasmid DNA onto transparent indium-tin oxide electrodes for temporally and spatially specific gene transfer. Langmuir 21(18):8360-8367.

Yoshikawa T, Uchimura E, Kishi M, Funeriu DP, Miyake M, Miyake J. 2004. Transfection microarray of human mesenchymal stem cells and on-chip siRNA gene knockdown. J Control Release 96(2):227-232.

Ziauddin J, Sabatini DM. 2001. Microarrays of cells expressing defined cDNAs. Nature 411(6833):107-110. 